\title{
Buckling Behavior of Steel Plates and Concrete Filled Composite Shear Walls Related Nuclear Power Engineering
}

\author{
XiaoHu Li, Yan Yuan \\ School of Civil and Architecture Engineering, Zhengzhou University of Aeronautics, \\ Zhengzhou, China \\ E-mail:xiaohu12066@126.com,250716109@qq.com
}

\begin{abstract}
Based on the program of nuclear power engineering, the in-plane buckling behavior of Steel plates and concrete filled composite shear wall (SCSW) was investigated. 9 1/5 scaled specimens were conducted under horizontal cyclic load and constant vertical load. The parameters such as the space of studs, the vertical load, the form of connectors, and the thickness of the steel plate were designed to research the affection on the buckling of the steel plate. According to the results of tests, it can be seen that the bulge of the steel plate occurred at about $50 \mathrm{~mm}$ above the top of the foundation beam. The bulge can be connected as a whole in the specimens with studs only, but not in the specimens with stiffeners. Finite element models were performed to simulate the buckling behavior of the steel plate, and the results were found to be in good agreement with the test results. The buckling stress of the steel plate was calculated by equations based on the measuring data. It was found that they were smaller than that of finite element analysis. The more accurate simulation was needed.
\end{abstract}

Keywords: Buckling behavior; Steel plates and concrete filled composite shear walls; Nuclear power engineering; cyclic load.

\section{Introduction}

Steel plates and concrete filled composite shear wall (SCSW) is a new kind of component to resist lateral force. It is mainly composed of two steel plates and the internal concrete. The welding shear studs inside of the steel plates are the mechanical connectors to ensure that the steel plates and the concrete can work as a whole. Unlike other engineering, the thickness of the SCSW related nuclear power engineering is greater (generally more than $1 \mathrm{~m}$ ) and the steel bars are not set inside the concrete. [1,2] presented that this structure not only has good seismic performance and shock resistance, and the application of modular construction techniques in the actual construction greatly improve the efficiency of construction. [3] Shows that the construction period can be reduced by $25 \%$ using the lateral steel plates as construction template when pouring the concrete. The excellent structural performance of SCSW driven that this kind of structure was more and more used in nuclear power engineering. The containment internal structures of AP1000 [4] and US-APWR [5] use SCSWs to shield radiation, to prevent damage in the earthquake, and to prevent the crash, etc.

The Japanese scholars first studied the SCSWs in the 1980s [6], and then many experimental and numerical studies on the seismic behavior of SCSWs were conducted for the last few decades [7-10]. But only limited researchers studied the buckling behavior of the steel plate of SCSWs. [11] studied the feasibility of steel-concrete composite structure for nuclear power plant buildings. 1/5 scaled SCSW specimens were conducted to research how to prevent buckling. It found that the strains both outside and inside the surface of the steel plate increased similarly before buckling. However, they separate suddenly after buckling. The peak steel stress values at the locations of the crack surfaces were calculated as [12].

$$
\sigma_{s \max }=\frac{T_{r m}}{2 t_{s}}
$$

where $T_{r m}$ is the maximum force and $t_{s}$ is the thickness of the steel plate.

Twelve specimens were tested with reasonable width-to-thickness of steel plates and properly arranged batten plates, it was found that there was no evident buckling can be observed on the surface steel plates, so these measures were proved to be effective to prevent the buckling of the steel plates [13]. Yue Yang [14] conducted 10 specimens to research the buckling behavior of SCSWs and the results showed that the arrangement and spacing of the shear studs had a significant effect on the buckling of the steel plates. Finite element models were also made to simulate the behavior of the steel plates subjected to axial pressure and the finite element results had a good agreement with the test results. Youjia Zhang [15] studied the buckling law of the steel plate of SCSW according 
to three different steel plate elastic buckling theoretical models. Based on the experiment and theoretical analysis, a formula of the strain was proposed for elastic buckling of the steel plate of SCSW as follows:

$$
\varepsilon_{C R}=1.3 \pi^{2} / 12(B / t)^{2}
$$

where is the space of the shear studs and is the thickness of the steel plate.

The above research is all relate to the buckling of the steel plates of SCSW under axial pressure. Few researchers studied the buckling of the steel plates of SCSW under horizontal cyclic loading. In this paper, 9 1/5 scaled SCSW specimens were conducted and horizontal cyclic loading tests were performed to study the buckling behavior of the steel plates and the damage form of the steel plates when the buckling occurs. The formula of critical buckling load of the steel plate was proposed based on energy method.

\section{Experimental program}

\subsection{Specimen design}

9 1/5 scaled SCSW specimens were designed and all the specimens were designed as the same geometry and all consist of 3 parts: loading beam, shear wall, and foundation beam. The size of each part is respectively $1020 \mathrm{~mm}$ $\times 300 \mathrm{~mm} \times 300 \mathrm{~mm}, \quad 820 \mathrm{~mm} \times 220 \mathrm{~mm} \times 2000 \mathrm{~mm}, \quad 1820 \mathrm{~mm} \times 430 \mathrm{~mm} \times 550 \mathrm{~mm}$, details of specimens are given from front view and side view of the specimen in Fig.1. The parameters of the specimen including the thickness of steel plate, stud space, vertical load, and the form of the connectors. The thickness of the steel plates was $4 \mathrm{~mm}$, $6 \mathrm{~mm}$, and $8 \mathrm{~mm}$. The geometry of the shear studs was diameter $6 \mathrm{~mm}$ and height $50 \mathrm{~mm}$, which were welded on the inside of the steel plates. The space of the shear studs was $60 \mathrm{~mm}, 100 \mathrm{~mm}, 150 \mathrm{~mm}$, and $200 \mathrm{~mm}$. The vertical load was $0 \mathrm{kN}$ and $800 \mathrm{kN}$. The form of the connectors was shear studs and stiffener. The design parameters of specimens were presented in Table 1.

\subsection{Material properties}

The steel plates used in the test were made of Q345 steel the concrete used in the walls had a strength grade of C55 (the nominal cubic compressive strength, fcu, $d=55 \mathrm{MPa}$ ). The Poission's ratio of the steel plates was 0.3 and the Poission's ratio of the concrete was 0.2. The elastic modulus of the concrete was $3.25 \times 104 \mathrm{MPa}$. The material properties of the steel plates and the shear studs used in the experiment are presented in Table 2.

\subsection{Loading process and failure modes}

In order to study the buckling behavior of the steel plate of SCSW, strain rosettes should be pasted on the location of the steel plate where the buckling was likely to occur. The stress of the steel plate could be calculated by the formula based on the strain measured. In the strain rosettes, the strain of $x$ and $y$ was respectively corresponding to the horizontal and vertical strain on the location of the steel plate. The arrangement of the strain rosettes is shown in Fig.2.

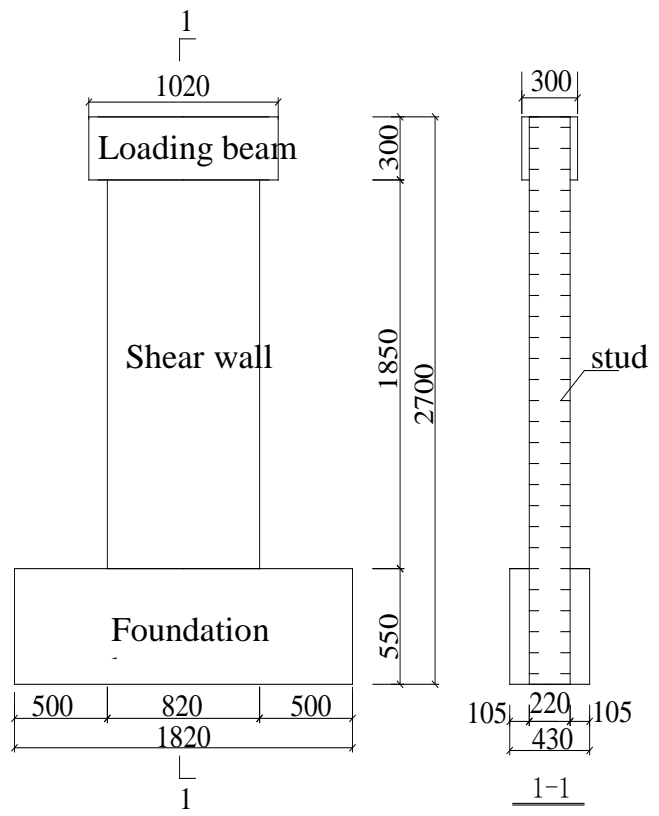

Fig.1. Elevation view of composite shear wall specimens (Unit: mm) 
Tab.1 Specimen parameters

\begin{tabular}{ccccc}
\hline Specimen no. & Thickness of steel plate $(\mathrm{mm})$ & Space of studs $(\mathrm{mm})$ & Vertical load $(\mathrm{kN})$ & Form of connectors \\
\hline SCSW1 & 4 & 100 & 800 & Shear stud \\
SCSW2 & 4 & 150 & 800 & Shear stud \\
SCSW3 & 4 & 200 & 800 & Shear stud \\
SCSW4 & 6 & 100 & 0 & Shear stud \\
SCSW5 & 6 & 100 & 800 & Shear stud \\
SCSW6 & 8 & 100 & 800 & Shear stud \\
SCSW7 & 4 & 60 & 800 & Shear stud \\
SCSW8 & 4 & - & 800 & Shear stud +stiffener \\
SCSW9 & 4 & - & 800 & stiffener \\
\hline
\end{tabular}

Tab.2 Material properties of steel plates

\begin{tabular}{cccc}
\hline Thickness of steel plates $(\mathrm{mm})$ & Yield strength $(\mathrm{MPa})$ & Ultimate strength $(\mathrm{MPa})$ & Elastic modulus $(\mathrm{GPa})$ \\
\hline 4 & 352.12 & 497.37 & 187 \\
6 & 348.33 & 494 & 197 \\
8 & 356.33 & 496.67 & 208 \\
\hline
\end{tabular}

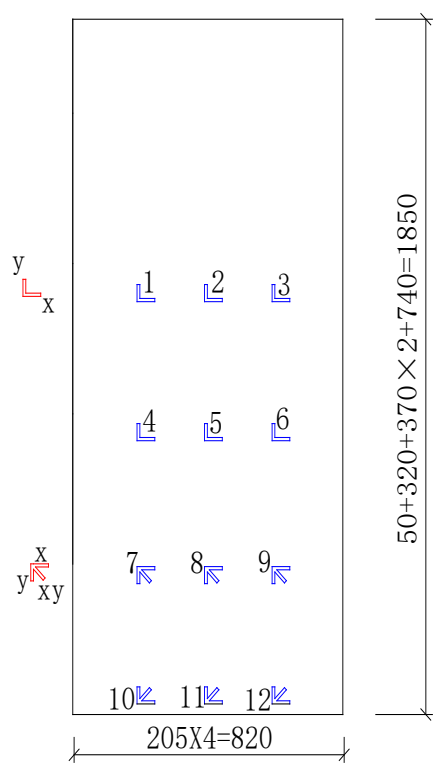

Fig.2 Strain test point arrangement of specimens steel plates

The experiment in this paper was conducted in Beijing Key Lab of Earthquake Engineering and Structural Retrofit. First, the SCSW specimen should be fixed on the floor by anchor bolt and then the vertical load of 800 $\mathrm{kN}$ was performed on the loading beam and the vertical load remained the same in the process of test. When the vertical load reached stability, the cyclic horizontal load was applied on the specimen step by step with $50 \mathrm{kN}$ till the specimens reached the yield point. The displacement of the top beam was recorded as $\Delta y$. Then the method of displacement control was used and the displacement step was $1 / 8 \Delta \mathrm{y}$. The loading process was stopped when the horizontal load reduced to $85 \%$ of the ultimate load. The loading device of the test is shown in Fig.3.

\section{Test results and analysis}

\subsection{Loading process and failure modes}

In the early stages of loading, the specimens were in elastic state and there was no obvious changes could be seen from the outside of the specimens. The load was increased continue and a hollow sound was made when the hammer was used to knock on the steel plate at the bottom of the wall. To continue loading, the bulge phenomenon occurred initially at the place above $50 \mathrm{~mm}$ of the foundation beam and close to the lateral boundary of the wall, it is shown in Fig.4. It can be found that the bulge place is close to the place where the strain rosette was pasted.

In the process of cyclic loading, the steel plates had bulges on the pressure side of the wall and the bulges were flattening on the tensile side of the wall. With the increasing of the horizontal load, the range of bulge increased gradually. The bulge occurred for local because of the existence of the shear studs and stiffeners at first, the concrete inside of the wall was crushed gradually and a horizontal crack occurred on the bottom of the steel plate. 
For the specimens with shear studs only, the bulge beat together when the shear studs were fracture. For the specimens with stiffeners, the local bulge was made and can not be conneted as a whole. Finally, the steel plate at the bottom of the wall was yield and the crushed concrete flowed from the cracks of the weld seam. It can be seen from the damaging phenomenon of the specimens, the failure mode of the specimens with shear studs only and the specimens with stiffeners is different. Fig.5 shows the failure modes of SCSW1 and SCSW8, they were the typical specimen.

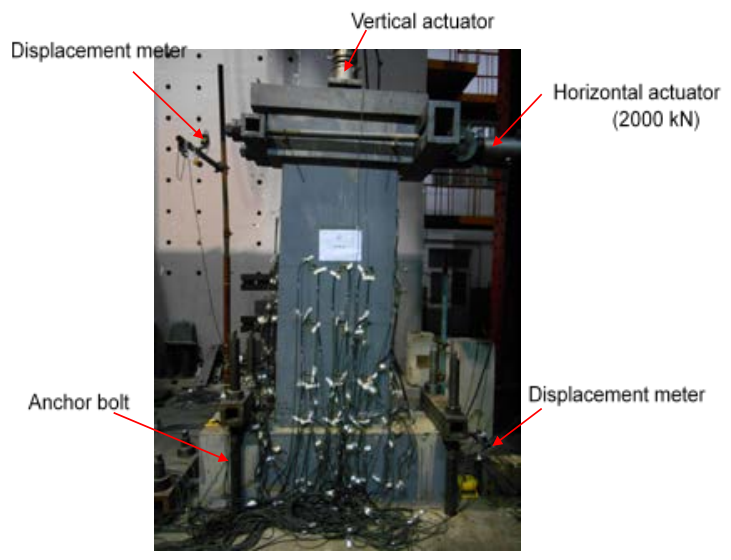

Fig.3 Load device of tests

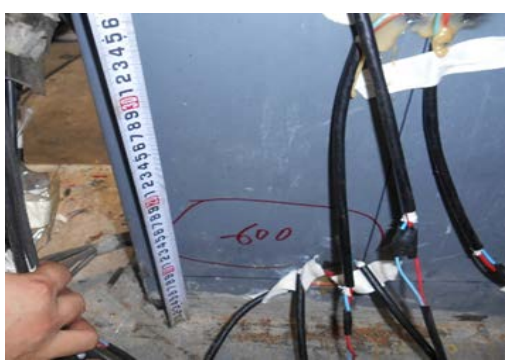

(a)First bulge of SCSW1

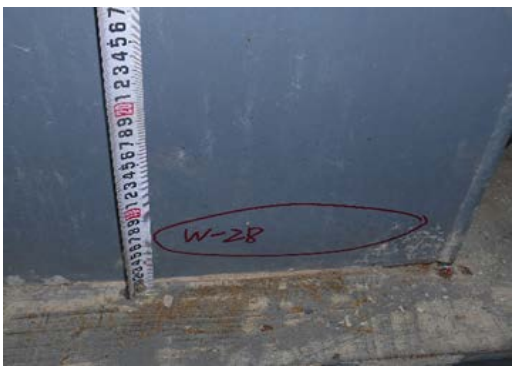

(d)First bulge of SCSW4

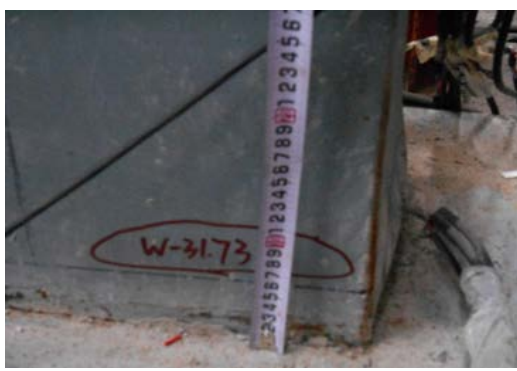

(g)First bulge of SCSW7

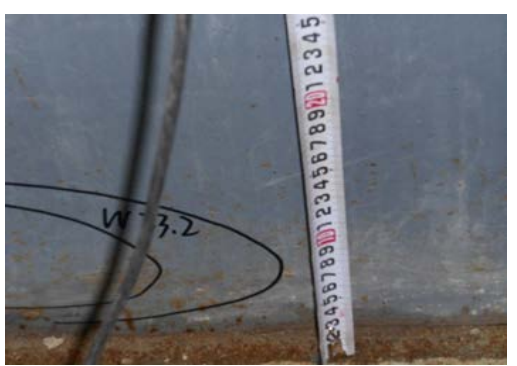

(b)First bulge of SCSW2

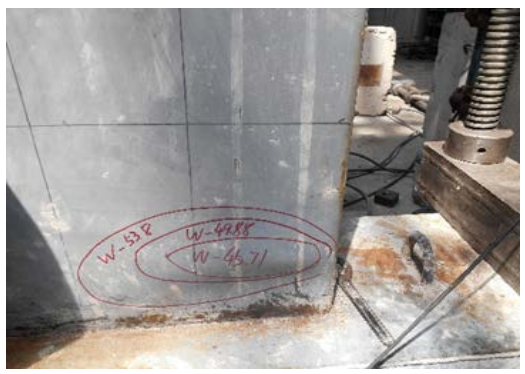

(e)First bulge of SCSW5

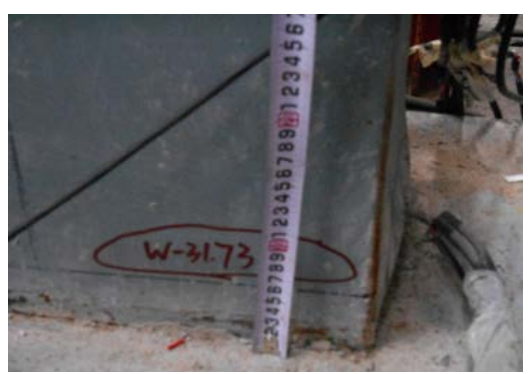

(h)First bulge of SCSW8

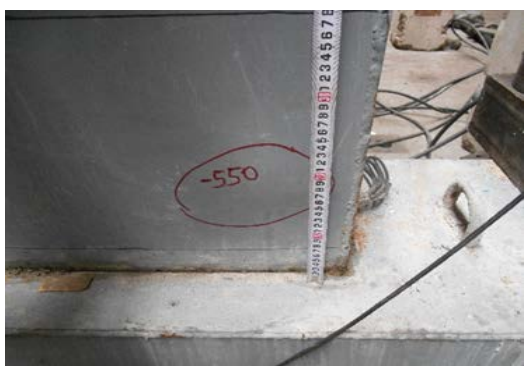

(c)First bulge of SCSW1

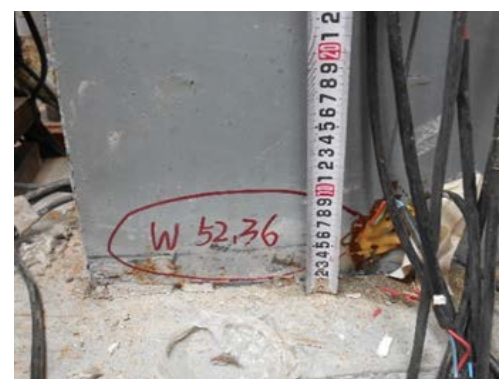

(f)First bulge of SCSW6

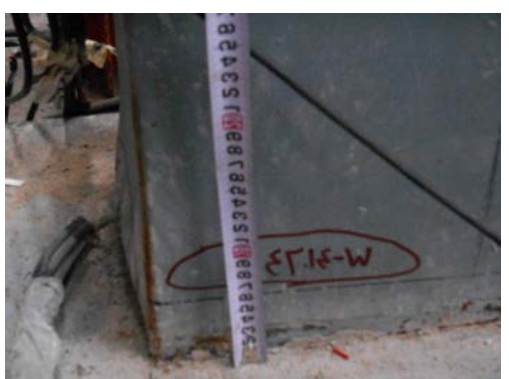

(i)First bulge of SCSW9

Fig.4 First bulge of SCSW specimens 


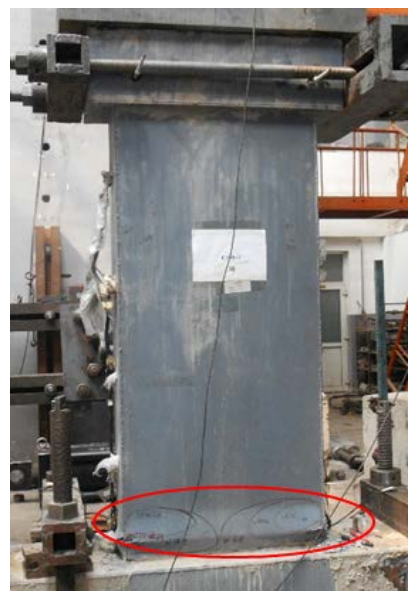

(a)Failure mode of SCSW1 (front)

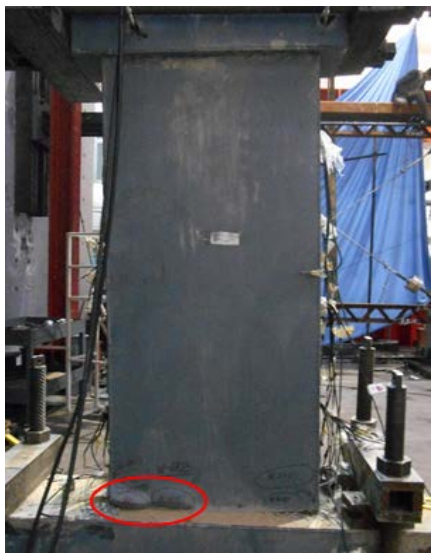

(c)Failure mode of SCSW8 (front)

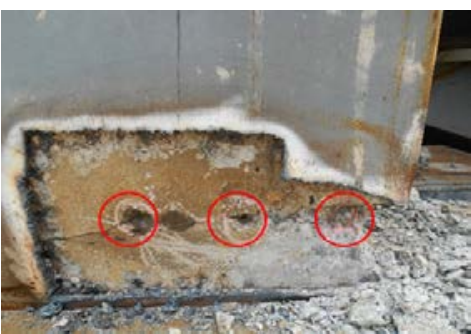

(e) Stud fracture

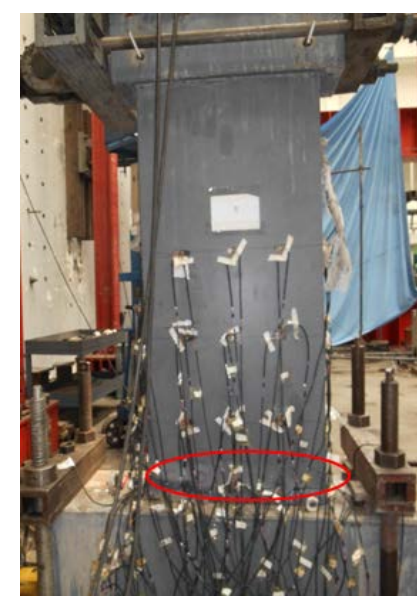

(b)Failure mode of SCSW1 (back)

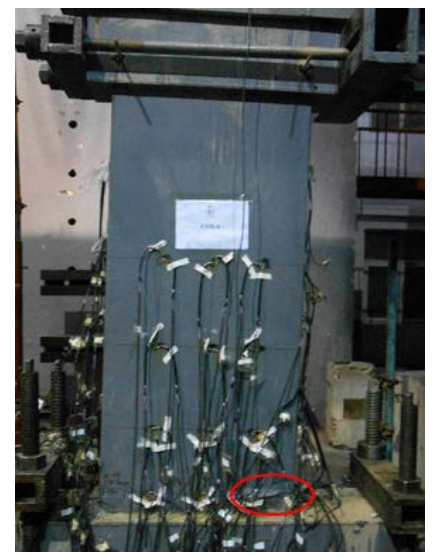

(d) Failure mode of SCSW8 (back)

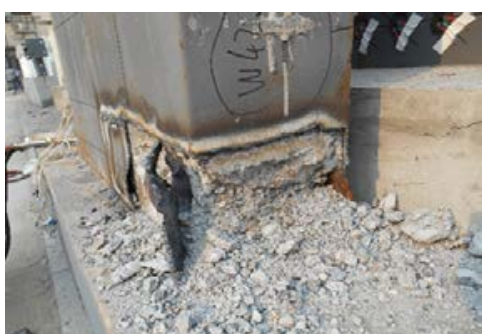

(f) Concrete crushing

Fig.5 Failure modes of SCSW specimens

\subsection{Analysis of the test results}

According to the test results, it can be seen that the location of the steel plate buckling occurred was closed to the bottom and the lateral boundary of the wall. Therefore, the horizontal load-strain curve of the measuring point 12 or 10 should be analyzed to research the buckling of the steel plates. A turning point will appear on the horizontal load-strain curve when buckling occurs on the steel plate. From the observation on the curves of horizontal load-strain, the point where buckling first occurs was identified as buckling point and the corresponding load was identified as buckling load. Fig. 6 shows the horizontal load-strain curves of the measuring point 12 on the steel plate. It can be seen from the experimental phenomena that the bulge position is located between the studs and the top surface

The stress of the steel plate reached a critical value. So the buckling load and stress of the steel plate can be obtained through analysis on the data of the turning point.

From the horizontal load-strain curve of the measuring point 12 of the SCSW specimens, it can be seen that only the curve in $\mathrm{x}$ direction has an obvious turning point and the curves in other two directions have not. So the position of the turning point appears should be confirmed in horizontal load-strain curve of $\mathrm{x}$ direction. The turning point in Fig.6 (c) is different from other specimens that the strain of the turning point is positive. The distance 
between bulge position and the position of strain rosette on the steel plate of SCSW3 specimen is so far that the measured data is not the buckling of the steel plate. So the strain of the steel plate can't be referred according to this data.

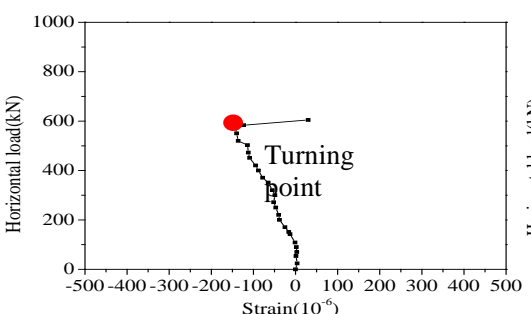

(a)SCSW1

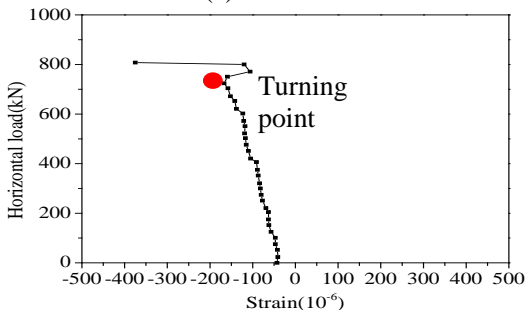

(d)SCSW4

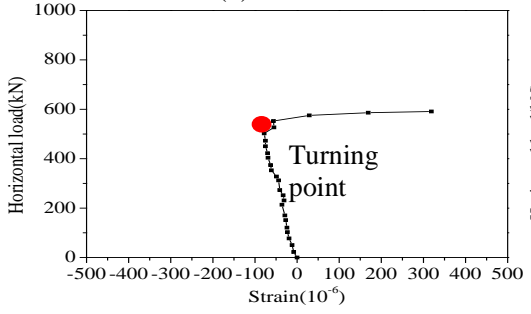

(g)SCSW7

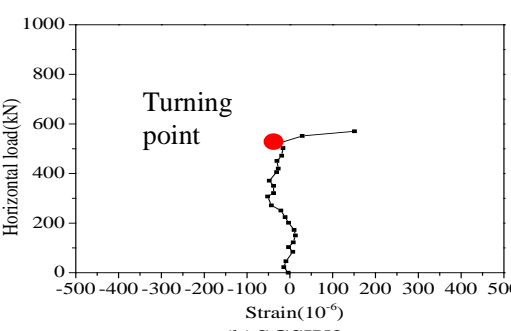

(b)SCSW2

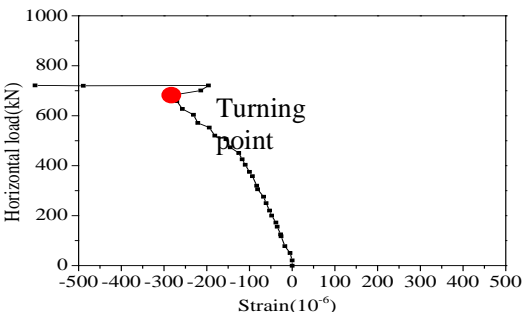

(e)SCSW5

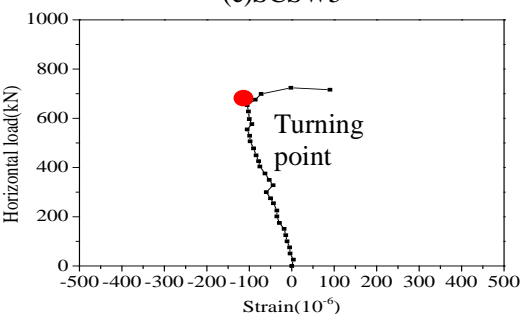

(h)SCSW8

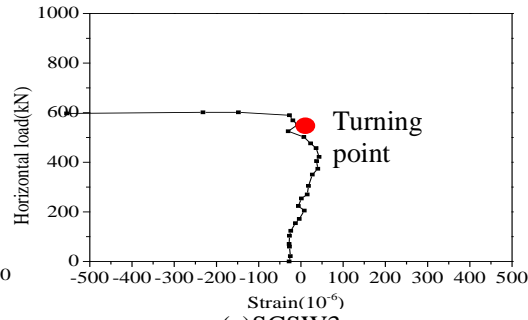

(c)SCSW3

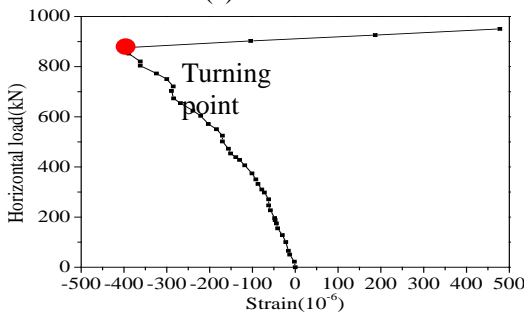

(f)SCSW6

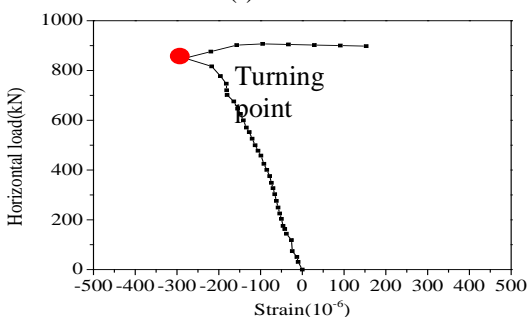

(i)SCSW9

Fig.6 The curves of horizontal load-strain of specimens

As can be seen from Fig.6, the buckling of the steel plate occurred before the ultimate load of the specimen. The buckling load of the steel plates and the ultimate load of the specimens is shown in Table.3.

Yue Yang [14] found that reasonable optimization to the arrangement form of the studs could improve the buckling stress of the steel plate. Different space of studs were designed to study the effects of studs on the buckling behavior of the steel plate. Comparing Fig.4(a)(b)(c)(h), it can be seen that the position of bulge on the steel plate is related to the minimum distance between the studs and the bottom boundary of the wall. The bulge is generally located in the center of the distance. From Fig.6(a)(b)(c) it can be found that the critical load on the turning point increased with the decrease of the stud space. It was proved that the decrease of the stud space could improve the buckling load of the steel plate slightly.

In Fig. 4(a)(d)(f), the positions of the bulge on the steel plate were very close, so the change of the thickness of the steel plate have no obvious impacts on the position of the bulge. Contrast Fig. 6(a)(d)(f), it can be found that increasing the thickness of the steel plate could improve the critical load of the steel plate and the ductility of the steel plate was also improved.

In Fig. 4(a)(d)(f), the position of the bulge on the steel plate of SCSW4 was lower than that of SCSW5. It showed that the increase of the vertical load made the bulge down. The displacement on the top of the wall of SCSW4 when the bulge first occurred is larger than that of SCSW5. It was explained that the increase of the vertical load could accelerate the damage of the specimen.

The stiffeners divided the steel plate into several parts and this increased the lateral constraint of the steel plates. Fig.4(a)(h)(i) indicates the position of bulge occurred. The positions of bulge of specimens with stiffeners is roughly similar, but the time bulge occurred of SCSW9 is later than that of SCSW1. According to Fig.5, it can be get that the stiffeners can effectively prevent the buckling of the steel plate. From Fig.6(a)(h)(i), it can be found that the critical load of the steel plate of SCSW9 have great improvement comparing with SCSW1, and the ductility of the steel plate of SCSW9 are also improved.

Based on the strain measurement of the steel plate, the buckling stress of the measuring point can be obtained by Eq. (3) and Eq. (4). From Fig.6, the strain of the turning point can be used. In theory, Eq. (3) and Eq. (4) are valid for elastic and plastic behavior. 


$$
\begin{aligned}
& \sigma_{1}=\frac{E}{2}\left[\frac{\varepsilon_{x}+\varepsilon_{y}}{1-\mu}+\frac{1}{1+\mu} \sqrt{\left(\varepsilon_{x}-\varepsilon_{y}\right)^{2}+\left(2 \varepsilon_{x y}-\varepsilon_{x}-\varepsilon_{y}\right)^{2}}\right] \\
& \sigma_{2}=\frac{E}{2}\left[\frac{\varepsilon_{x}+\varepsilon_{y}}{1-\mu}-\frac{1}{1+\mu} \sqrt{\left(\varepsilon_{x}-\varepsilon_{y}\right)^{2}+\left(2 \varepsilon_{x y}-\varepsilon_{x}-\varepsilon_{y}\right)^{2}}\right] \\
& \sigma_{0}=\sqrt{\sigma_{1}^{2}+\sigma_{2}^{2}-\sigma_{1} \sigma_{2}}
\end{aligned}
$$

where $\mathrm{E}$ is the Young's modulus of the steel plate, $\mu$ is the Possion's ratio, $\varepsilon_{x}, \varepsilon_{y}, \varepsilon_{x y}$ is the strain of steel plate in $x, y, x y$ direction, just as shown in Fig.2, $\sigma_{0}$ is the principal stress in the turning point. Table.4 shows the calculated results of the buckling stress of the steel plate.

\section{Finite element analysis}

Numerical simulations of SCSW specimens were conducted using the finite element software ABAQUS in this paper. The steel plate, concrete, stud, and the stiffener were modeled using the linear hexahedral element (C3D8R). Some simplified processing was made on the specimens. The deformation of the loading beam on the influence of the wall is ignored because that the stiffness of the loading beam is strong enough. The anchor bolts were used to fix the specimens in the experiment, but there would be a slight slide of the foundation beam in the process of loading. The deformation and slight slide of the foundation beam would be ignored and fully fixed boundary on the foundation beam was adopted in the numerical analysis. The loading point was created in the center at the top of the wall and it was coupled with the tip section of the wall. This was the position where vertical load and the horizontal load was set. Monotonic loading mode and displacement control were used for horizontal loading.

There were two steps of the analysis. First, the vertical load was applied to the loading point. Second, the displacement control was used to set horizontal load and this could achieve the same effect with force-displacement control. Fig.7 shows the boundary and loading form of the shear wall.

Table.3 The buckling load of the steel plates and the ultimate load of the specimens

\begin{tabular}{cccc}
\hline Specimen no. & Buckling load of the steel plate $(\mathrm{kN})$ & Ultimate load of the specimen $(\mathrm{kN})$ & Buckling load / Ultimate load \\
\hline SCSW1 & 563.06 & 609.9 & 0.923 \\
SCSW2 & 551.29 & 598.6 & 0.921 \\
SCSW3 & 421.81 & 596.95 & 0.707 \\
SCSW4 & 662.75 & 804.4 & 0.824 \\
SCSW5 & 667.56 & 728.7 & 0.916 \\
SCSW6 & 866.55 & 958.4 & 0.904 \\
SCSW7 & 575.28 & 612.4 & 0.940 \\
SCSW8 & 689.29 & 744.3 & 0.926 \\
SCSW9 & 785.98 & 906.8 & 0.867 \\
\hline
\end{tabular}

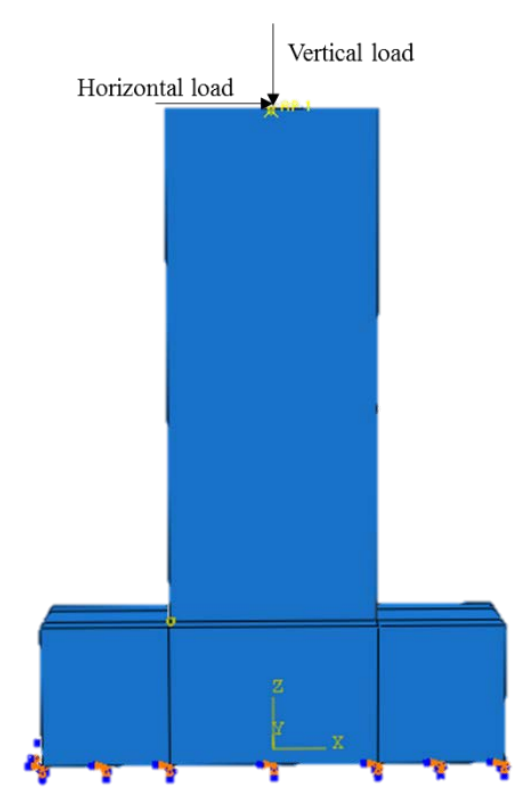

Fig.7 Boundary conditions and loading form 
Table.4 Buckling stress of the steel plate

\begin{tabular}{cccc}
\hline Specimen no. & $\sigma_{F}(\mathrm{MPa})$ & $\sigma_{t}(\mathrm{MPa})$ & $\sigma_{F} / \sigma_{t}$ \\
\hline SCSW1 & 400.8 & 337.1 & 1.19 \\
SCSW2 & 402.16 & 314.0 & 1.28 \\
SCSW3 & 400.37 & 305.3 & 1.31 \\
SCSW4 & 400.29 & 329.19 & 1.21 \\
SCSW5 & 401.06 & 353.63 & 1.13 \\
SCSW6 & 399.96 & 384.95 & 1.04 \\
SCSW7 & 401.02 & 348.52 & 1.15 \\
SCSW8 & 400.31 & 353.57 & 1.13 \\
SCSW9 & 402.81 & 353.53 & 1.14 \\
\hline
\end{tabular}

Where $\sigma_{F}$ is the buckling stress of the steel plate of finite element analysis, $\sigma_{t}$ is the buckling stress of the steel plate of the test.

Through numerical analysis of the stress of SCSW specimens, the failure mode of specimens and the buckling of the steel plate were obtained, just as shown in Fig.8. Comparing the failure mode of specimens of numerical simulation with the experiment, it can be found that the position of bulge appears is very close with each other, both of the position of the bulge is $50 \mathrm{~mm}$ above the top of the foundation beam. The horizontal load-strain curves were obtained according to calculation and Fig.9 shows the horizontal load-strain curves both of finite element analysis and test. It can be seen that the shapes of the calculated results are similar to those of the test results. The calculation results of the stress according to the strain measurement were compared with the numerical simulation results, the simulated stresses were higher than the measured ones, because the initial imperfection of the materials were not considered in the finite element analysis. The concrete would be failure when it was crushed in the actual experiment, however, the concrete still had strength in the numerical simulation.

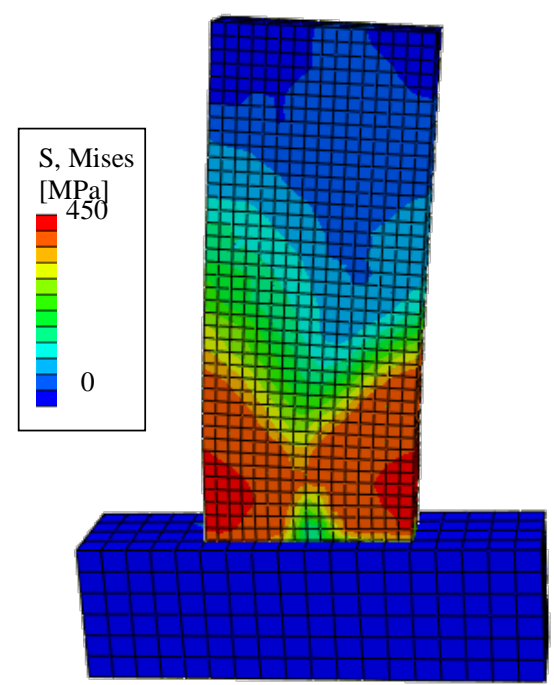

(a)SCSW1

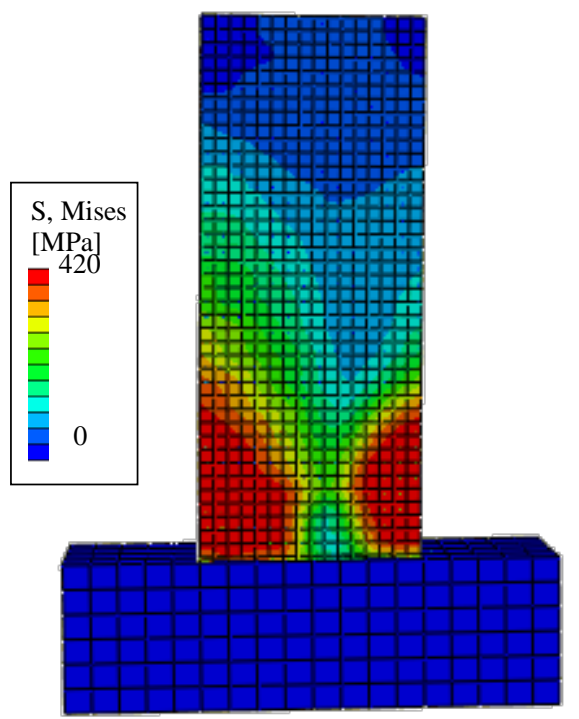

(b)SCSW8

Fig.8 Failure mode of the specimens

\section{Conclusions}

Experiment and finite element analysis were conducted on the buckling behavior of the steel plate of SCSW specimens under horizontal cyclic load. Based on the results of numerical analysis and test, the main conclusions in this research were drawn as follows:

1) The experiment results showed that the position the bulge occurred 50mm above the top of the foundation beam, the local bulges were connected as a whole in the specimens with studs only and were not in the specimens with stiffeners. It can be seen from the results that the buckling load of the steel plate is lower than the ultimate load of the specimens.

2) The space of studs, vertical load, the form of connectors, and the thickness of the steel plate have an effect on the buckling of the steel plate.

3) Finite element modulus was performed to simulate the buckling of the steel plate. Comparing the finite 
element results and the test results, it was found that both agreed well with each other. The position of the bulge of the steel plate is very close but the strain of the steel plate of finite element simulation is different from the test. This is limited by the test condition and simplified modulus in the simulation. So a more accurate simulation is needed.

4) The calculated buckling stress of the steel plate by Eq.(3) and Eq.(4) were compared with the results of finite element analysis, it was found that the former was smaller than the latter. This is due to the initial defects of the materials. Cumulative damages exited in the process of test, but this was neglected in the finite element model.
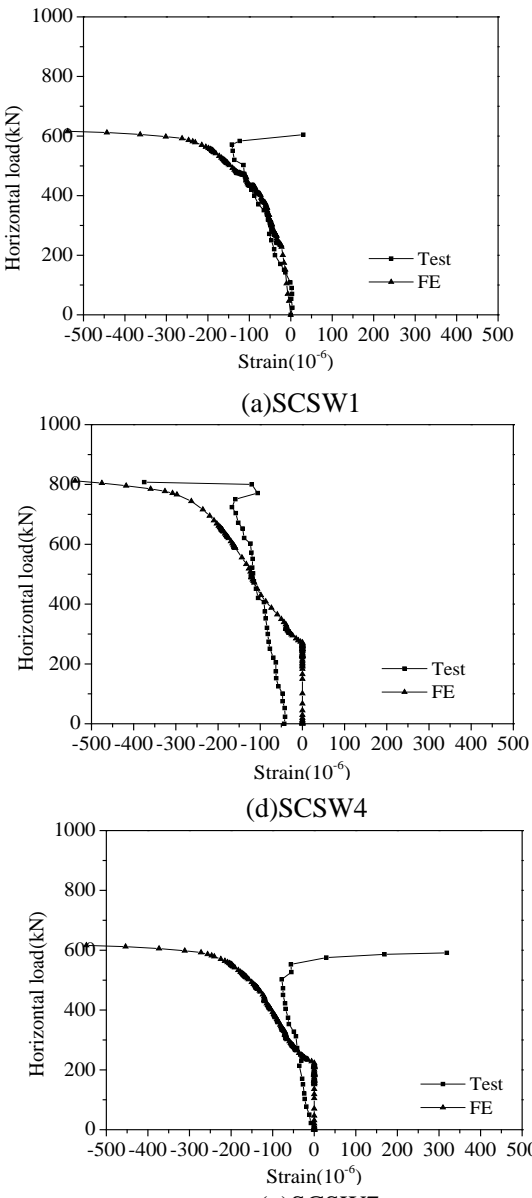

(g)SCSW7

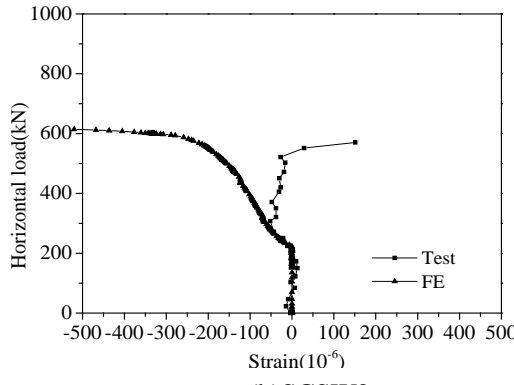

(b)SCSW2

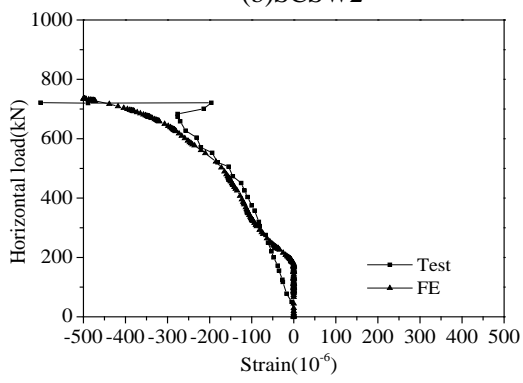

(e)SCSW5

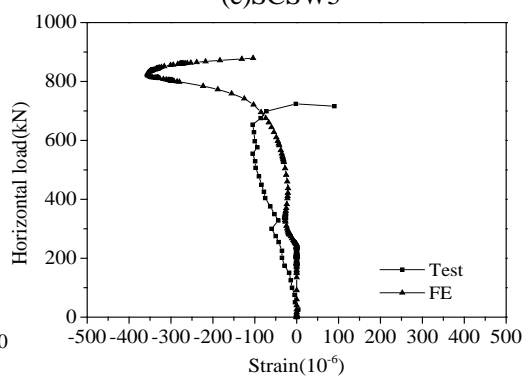

(h)SCSW8

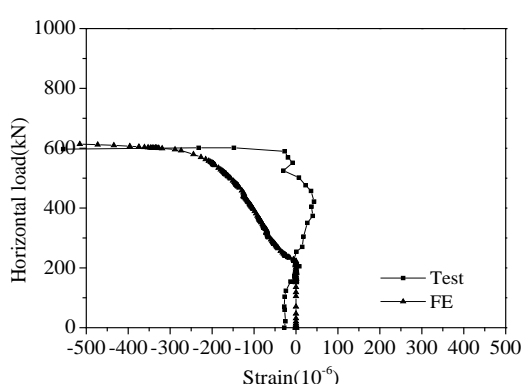

(c)SCSW3

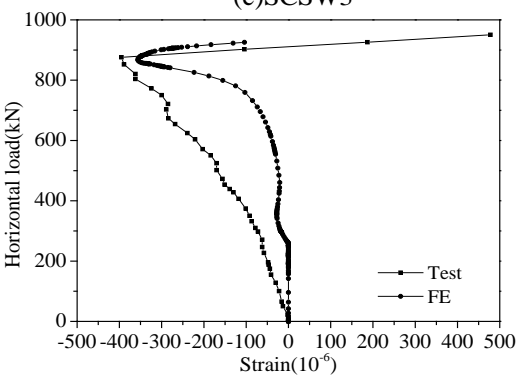

(f)SCSW6

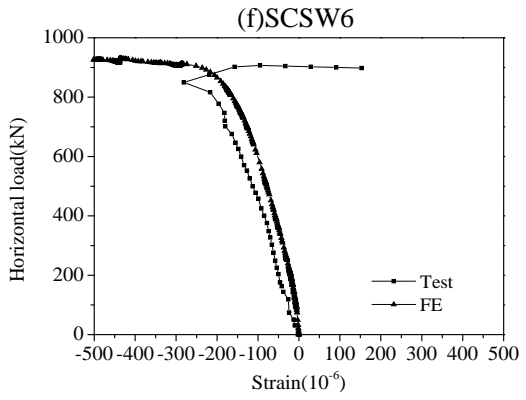

(i)SCSW1

Fig.9 Horizontal load-strain curves both of finite element analysis and test

\section{Acknowledgements}

The study reported here is financially supported by the Foundation for Innovative Research Groups of the Natural Science Foundation of China (Grant No. 51421005), National Science and Technology Major Project of China (Grant No. 2013ZX06002001), the plan to build innovation team of Beijing municipal institution (Grant No. IDHT20130507). The support is gratefully acknowledged.

\section{References}

[1] Ozaki M, Akita S, Oosuga H, Nakayama T, Adachi N. Study on steel plate reinforced concrete panels subjected to cyclic in-plane shear. Nucl Eng Des 2004, 228 (1-3): 225-44.

[2] Ji X, Jiang F, Qian J. Seismic behavior of steel tube-double steel plate-concrete composite walls: Experimental tests. Journal of Constructional Steel Research, 2013, 86(6):17-30.

[3] Braverman J, Morante R, Hofmayer C. Assessment of modular construction for safety-related structures at advanced nuclear power plants. U.S. Nuclear Regulatory Commision. Washington, DC, USA. 1997.

[4] DCD. Design control document for the AP1000. Washington, DC, USA: U.S. Nuclear Regulatory Commission; 2011.

[5] DCD. Design control document for the US-APWR. Washington, DC, USA: U.S. Nuclear Regulatory 13 
Commission; 2012.

[6] Frank J. Vecchino, Ian McQuade. Towards improved modeling of steel-concrete composite wall elements. Nuclear engineering and design. 2011;241: 2629-2642.

[7] H.D. Wright, T.O.S. Oduyemi, H.R. Evans. The experimental behavior of double skin composite elements, J. Constr. Steel Res. 1991;19 (2): 97-110.

[8] S.K. Clubley, S.S.J. Moy, R.Y. Xiao, Shear strength of steel-concrete-steel composite panels: part I - testing and numerical modeling, J. Constr. Steel Res. 2003;59 (6): 781-794.

[9] J.G. Nie, X.W. Ma, M.X. Tao, J.S. Fan, F.M. Bu. Effective stiffness of composite shear wall with double plates and filled concrete, J. Constr. Steel Res. 2014; 99.

[10] K.C. Sener, A.H. Varma, Steel-plate composite walls: experimental database and design for out-of-plane shear, J. Constr. Steel Res. 2014;100: 197-210.

[11] Takeuchi M, Narikawa M, Matsuo I, Hara K, Usami S. Study on a concrete filled structure for nuclear power plants. Nucl Eng Des 1998; 179(2):209-223.

[12] Danay A. Response of steel-concrete composite panels to in-plane loading. Nuclear Engineering \& Design, 2011, 242:52-62.

[13] Nie J G, Hu H S, Fan J S, et al. Experimental study on seismic behavior of high-strength concrete filled double-steel-plate composite walls. Journal of Constructional Steel Research, 2013, 88(9):206-219.

[14] Yang Y, Liu J, Fan J. Buckling behavior of double-skin composite walls: An experimental and modeling study. Journal of Constructional Steel Research, 2016, 121:126-135.

[15] Youjia Zhang, Xiaojun Li. Axial Compression Experimental Study of Composite Walls Based on Steel Plate Elastic Buckling Theory. Journal of basic science and engineering,2015, 23(6):1198-1209. (in Chinese) 